\title{
Interview
}

\section{Asset management and metadata workflow - An interview with Andrew Gregory of eMedia Concepts}

\begin{abstract}
Andrew Gregory
began his 18-year career in digital media services at the beginning of the digital media explosion. At the age of 22 he was a partner of a small advertising agency, Gregory \& Wahl, Ltd. The very intense beginnings as the production manager helped mold his knowledge of media production from the ground up, with the workflow in mind. His path has led through the Digital Photography (Sales and Marketing Director for Bartlett Digital Photo), Digital Prepress (Vice President Blackhawk Color) and Digital Asset Management (National Solutions Specialist - WAM!NET, also WebWare Corp - Senior Account Manager) boom. His love for the ever-changing environment of digital workflow processes led him to the rich media/video publishing movement. Gregory's perspective on the convergence of media over the years has afforded him the opportunity to work with all levels of many international organizations. Those include: Discovery Education, AOL, PBS, Rodale Publishing, Glaxo SmithKline, First Union (Wachovia), Ryder Transportation, Lyrick Studios (Barney), Tyson Foods, Scripps Howard (HGTV), The Weather Channel, PBS, Verizon, JC Penney, Sea World, Sam's Club and Stars \& Stripes.
\end{abstract}

\section{ABSTRACT Michael Moon interviews Andrew Gregory, of eMedia Concepts on topics around the future of asset management and metadata workflow.}

Journal of Digital Asset Management (2009) 5, 148-158. doi:10.1057/dam.2009.7

Keywords: asset management; metadata; workflow; video; broadcast; DAM

MM: We're here with Andrew Gregory.

Andrew - give us a little bit of your professional background.

AG: I am a digital media professional with a background in asset management and metadata workflow. I've parlayed that into supporting my video publishing expertise, now.

MM: What's your background with respect to analytics and workflows that are related to DAM and/or policies and so on?

AG: My background began with the digital revolution. I have fundamental understanding of the different workflows for metadata starting with print media and now for the last 3 years video. What I have found, and it is most interesting, is that metadata elements are the underpinnings of all of those different types of workflows. If we don't understand what's happening with the metadata. We don't know where it's going or how intelligent it is going to be when it gets there.

MM: As metadata relates to media and content, how is that different, as it relates to video and online video?
AG: It's similar and it's different, at the same time. It's similar in that you have file specifications that are in both areas - which are very similar structurally. But it's also different because it's much more dynamic and far-reaching, with respect to the search capabilities to access that - and how intelligent that particular content piece is when you start digging deeper.

Rich media and video or that type of content has so much more context to it than what is typically searchable.

MM: In many respects, some of the most interesting and powerful and useful metadata relates to the context of the particular content contained in the video frame or the sequence. What are some of the contextual things that you find video publishers or video content-users want to know about the context?

AG: Most of the time my clients typically just want to know what is in that particular piece of video. Typically, 'Did this piece of content talk about JFK and the grassy knoll? And where, in that particular video, does that segment start and end?' 
They are not wanting semantic indexing or meaning-based indexing from that asset. Typically, they want to know, 'What is this?' Not, 'What is this as it relates to something else and how can I link the two? However, we are getting there.'

MM: That semantic tagging probably occurs down the line. Specifically, where you have a webpage or document in which somebody has embedded the video. So you're not just looking at the video metadata in the video, but the written, textual information that surrounds the video.

How about if you give us a quick survey of what we call the 'video ecosystem,' or the 'video business ecosystem.' Who are some of the key players and what are some of the shifts that you see underway?

AG: As I see it, the video ecosystem is all the items that effect the inbound to outbound components of online video - then wrapping a dollar amount around that.

What I mean by that is, at the beginning of the ecosystem, you have to take content and get it into a format that's useable online. Is that content coming in from removable media - from old legacy archives? Or is it coming in from some sort of digital archive?

You have to get it into a homogenous format, such as Flash or Windows Media. That format then has to be published somewhere.

So the ecosystem starts at acquisition and moves to the center with storage and media management/metadata as management elements. And by having a homogenous delivery mechanism service providers and customers will have the ability get the content back out and it, and publish.

MM: Who are some of the well-known vendors and/or service providers?

AG: Well ... For Video Platforms Maven Networks. VMix, OnStream, BrightCove and Ooyala.

And For Ad Networks - 24/7 Real Media, Google, Doubleclick, TremorMedia and Tribal Fusion.

And For Content Delivery - Akamai, Limelight, Level 3 and CDNetworks.

And For Search, syndication and SEO there are a multitude of providers that can fit your needs.

These firms do bits of the eco-system. Not one firm does it all.
Most important ... files have to get in the system, they have to be converted and they have to be delivered so that they can be monetized.

MM: So there's a whole cluster of companies that just focus on digitizing legacy video.

Be it tape or DVD?

AG: Correct.

MM: As well as companies that deal with user-generated video.

AG: Correct.

MM: Then of course typical satellite or broadcast feeds, where you're simply grabbing it off the air and digitizing it.

AG: Correct.

In each one of these different styles of the ecosystem, there are those that are acquiring. And then there are those that play it back from a platform. Each platform has to then play it, and the delivery mechanism has to get it to the end user. The competitors for those types of platforms include Feedroom, Maven, BrightCove and OnStream, Ooyala and now Mogulus. These are the different types of competitors that are in that particular platform space.

The interesting point about it is, that each platform takes inbound and provides outbound video publishing delivery. The platform is the center point for their video content-management system.

MM: You're referring to The Platform as the Platform Company?

AG: The Platform Company is one of the platforms. It's interesting they call themselves the 'Platform,' but they are one of the group. That is correct.

They provide services that are managing assets, converting those assets, and then being able to publish them in different formats and different license-base, categorized structures. MM: As we look at this video ecosystem, both in terms of inbound and outbound and distribution, could you talk a little more about the process of video publishing? Specifically, what are some of the aspects that are unique to IPTV, mobile, social media and so on? AG: The biggest key component that's not been really tweaked very well is the essence of the asset.

When you think about where things have been - we've just been publishing, in my 
opinion, garbage. The essence of the asset or the content needs of an asset still need to be expressed in its best form. Right now, the partners and the platforms that are working on it aren't doing that in a quality form.

I mean that they're taking the original asset, maybe broadcast or high-definition film, and really bringing it down to a quality set that is very, very much a subset of the original element.

The areas of growth are going to be in quality of the assets, and the essence of that. When you look at the overall platforms that are delivering that content today, they're not doing a really good job at that. In general, social media platforms are providing low quality content. That low quality subset of video content is, I think, is going to be a fad. The growth areas will be addressing the quality. The essence of the asset needs to be expressed either at the desktop, the mobile or the plasma, in its best format. Right now, that's not being done very well.

MM: That kind of follows the traditional adoption patterns of most technology and certainly most digital media technology. Some of us are old enough to remember when multimedia CD ROMs were the new thing, and how video on that was not much larger than an African postage stamp, and grainy as hell.

AG: Right.

MM: Then as people started to understand that you could do this, and they wanted more better - different versions of it, the technology with each successive year. That trend will obviously continue.

Right now, we're kind of in the AM-Radio version of video. We'll certainly move up the quality curve.

I'd like you to speak to us a little bit on the uses of video. Most of us certainly have the experience of video from television broadcasts. That just recently has gone through a fairly significant change, in that many of us now have large plasma displays. Theatre-like displays.

We're seeing broadcasts that are now delivered in high-definition digital formats. Also, video's begun to move into the cinemas. As well as onto the Internet.

This gets to the idea that oftentimes from a creative production/post-production environment, what works well in television doesn't really work well in a theatrical setting. Then certainly in terms of the stories that you want to tell, it doesn't work well in mobile or on the Web.

What sort of innovations have you seen, Andrew, in terms of creating video assets that are either multipurposed or multiple takes on the same scene? Where each take is really optimized for the sense ratios?

AG: Understood.

The challenge to your question is really dual in nature. You have two sides of a coin with content. You have development resources and creative resources. At times, they are very much at odds with each other.

Creatives are needing to do something quick and easy, and need simple-to-use interfaces that make that happen. That's the 'Flash' genre. Creatives need to be able to deal with that in a very simple format.

But you're in an environment where as you go up in quality, the content becomes resource-heavy. The deep and dark functionality of moving it up the curve of quality is difficult.

The creative side of the house says, 'Okay. I want something really easy to use.' That then truncates the ability to get a rich experience. Which leads you into the development side of the house, and the ability to create applications or services for a higher-scale model.

Those two sides of the fence are Flash. Easy. Creatives are able to work with it. High-quality stuff, to a certain point. Then you start getting into resource management issues.

The development side is really about where SilverLight falls. Rich experiences. Longer-tail content. More interactive and more developer-centric. The value moves up the chain.

So the differences fall into what technology I'm going to use as compared to what experience I'm going to present. Which leads you into a conundrum. 'Is there something in the middle?'

Right now, the only thing that I'm seeing that's kind of in the middle is H.264. That file format, with respect to video content.

It's always creative versus development. But at the same time, we're trying to find that middle ground, and that's really leading us into certain formats that are being fleshed out at this point in time. Right now, that's really leading us into a codec setting of H.264. 
MM: There are really two parts to that that I'd like to continue to explore. One is more of an organizational design issue. We've run into this both at a large video game company and a large consumer-electronics company.

The Web teams that really just do online content now spend millions and millions of dollars a year sourcing, producing and publishing video content that has no reuse in any environment but the online environment.

They're shooting a Slice of Life or a user scenario B-roll. Or demonstrations. These could easily - if shot and managed properly - support in-store product demonstrations. Kiosks. Things you could do in ads before a movie. Or even an infomercial or some other sort of broadcast.

But because it was shot quick-and-dirty with the idea to just get content online, it lacks the production value. And it oftentimes lacks the actual data by which to support higher-resolution formats.

AG: Yes.

MM: That's one issue. That seems to be how companies are beginning to rethink how we actually buy, source and create video to use in our various communications and engagement systems.

The second one has to do with the constraints that the technology-publishing formats impose. Clearly, we have Flash broadly adopted and widely accepted. Well understood for getting video and animations to the Web quickly.

As I understand it now, with Creative Suite 4, the idea in Acrobat 9 is to publish Flash files into a PDF. That thereby gives it some persistence, but still some policy controls over what's going on with it.

AG: Yes.

MM: Then you mentioned Microsoft SilverLight. Because it's new, it hasn't had anywhere near the uptake or adoption. Their claim to fame was that it would support high-definition TV as a stream - if I understood that right? Aside from that, it had limitations or constraints for things that were simply not baked into it - when you compare it to a more mature, robust Flash platform.

AG: Yes. You've got that exactly correct. MM: To your point, Microsoft being Microsoft, they understand the pivotal role that third-party developers and fourth-party solution providers have in terms of completing a platform in more or less an end-to-end experience.

In the SilverLight platform, what has Microsoft done that's exceptional? And where are they coming up short, with respect to addressing the requirements of this ecosystem of third-party developers and fourth-party service providers?

AG: Let me address your second question first.

With respect to what Microsoft's doing with SilverLight, I think that primarily, they have kept in mind the developer community. Really, they're thinking about the current solutions that they have in place in front of them. That helps them go in and have rich application development policies, and different types of toolkits that are easily adopted for the SilverLight experience.

MM: For example, one of the newer developments is the ability to have a rich Internet application that gives you an immersive experience. But instead of it just being, 'Dead content playing on the screen,' you can embed into the stream hooks into databases, and other kinds of live applications - technically speaking. Such that the player experience maintains its state with backend Web services and databases.

Is that an innovation that's more developerfriendly?

AG: That's correct.

MM: Is that implemented well in the SilverLight platform?

AG: Based on my experience with my internal operations team, they're more pleased with it as compared to other products - as far as that type of functionality.

It seems to be that that rich experience and the openness of the toolkits makes the probability of that far greater than the current environment that we're in.

To go on, the experience of making sure that content is captured and then set up to be appropriately re-expressed. When I advise customers, I think of it in three different prongs - the archive standard, the mezzanine standard and the proxy.

The archive is for when I need to have something of a high-enough quality that I can come back to over a long period of time.

But it's going to be deep and dark, and I want to come back to it over that period 
of time. Currently, we're advising a JPG 2000 codec set.

If you have the appropriate algorithm or setting, you should be able to get back whatever you want over that period of time. That's number one.

Secondly, when you start talking about the mezzanine or the master standard for a short-term 36- to 48-month kind of window of reusing that content, and transcoding it into an expression that's usable.

We kind of fluctuate between two different environments. Typically, it's 5 megabits in capture. It can be an MPG 2. But just recently, not something new but something that's actually being brought out of the woodwork from 2001, it's a photo JPG environment codec. Mezzanine standard file formats allows for the file to be a little bit lower bit rate - but you're able to get a high-quality proxy out of that over time.

Then your proxy standard - which is your everyday use on the Web, or the iPhone. We're typically advising that the standard be either Windows Media, Flash, and right now, H264. That's a wonderful proxy setting, at some decent bit rates. Right around $750 \mathrm{kbps}$.

MM: Before we dive into H264, could you bring us up-to-speed on what's going on with Real Networks?

AG: Real - as far as my customers - is falling off relatively rapidly. Is it because it's old technology? I'm not sure that's it. Is it because it's just not the hottest thing on the block and not everybody's talking about it? I think that's more appropriate.

We have several clients of ours that still have legacy libraries all the way up to 2005 in Real format, but nobody is utilizing the player experience. Nobody's utilizing the actual tools, themselves. They're almost old technology in the way that people perceive it.

MM: Also, in that same vein, could you bring us up-to-speed on QuickTime and how that plays in the video ecosystem, these days? AG: QuickTime's playing pretty strongly, as a matter of fact. When you start talking about the production end of things, and being able to work with toolkits at the desktop a lot of in-house production environments are dealing with QuickTime as a standard to manipulate, push/pull and pass this on from agencies to going-to-post houses, and then back to a service provider like ourselves.

It seems to be a very interesting standard that's popping up because of the toolkits that are so easy to use in the marketplace. That's what I'm seeing or feeling in the marketplace. MM: So obviously, that speaks to the broad adoption of FinalCut among consumers.

AG: Correct.

MM: Final Cut Pro and Final Cut Server in the more commercial environments.

AG: Correct.

I'm not sure if the chicken or the egg brought them there, but it seems that they're definitely playing back-and-forth with each other. Correct.

MM: In terms of video on the Web, do you find QuickTime on the Web a popular format? Or is it the point that they switch to Flash and other forms of streaming media?

AG: Right now, I'd say 90 per cent of our requests are Flash. We are converting out of the QuickTime format. Flash is being utilized because it's so ubiquitous in all of the browser experiences.

MM: This begins to shape up - like the old videotape - where all the pro environments were on Sony Beta. Then as soon as it got out to the consumer plate, it shifted to the other video formats.

AG: Yes. However, we go back to that same issue of the essence of the content and the limitations of certain formats.

Currently, unless you're using an (Air) product, you have some limitations with respect to DRM and the control of that particular asset. Unless you're doing some secure streaming RTMPE-type streaming and the like, and then you're having issues with respect to controlling that asset. Unless you go into Windows Media type format, and the DRM that's wrapped around that.

MM: That's another thing to address. Does the Windows Media Player remain a fairly strong file format? If so, where on the ecosystem do you see it continuing to maintain or surge ahead, and where do you see it falling off? AG: I see it maintaining. It's really that middle-ground codec that we're doing a lot of our mezzanine standards on. That master standard sits and we transcode out of it, right now. 
I see it staying in the ecosystem at that level. However, I do see some of the other file formats taking over in the delivery online, as compared to Windows Media. But they are all going to play into a certain subsegment in the environment.

You're talking about a developer environment as compared to expression or creative. That comes back into that discussion again.

MM: So as we've talked about it, we've basically got three levels. We have the archive, long-term asset-management level. There, you have files stored in high-definition formats to the extent that it is high-definition.

This embraces, as you said, a JPG 2000 (lossless) format standard.

AG: Yes.

MM: Then on a middle or mezzanine level, you have a number of workflow-oriented file formats. QuickTime and Windows Media being strong ones.

Are there any other strong workflow file formats at the mezzanine level, as you're seeing it?

AG: Not that pop up on a day-in and day-out basis. You'll from time-to-time get requests for the outliers such as in the photo JPG. But that's the esoteric mindset.

Typically, QuickTime and Windows Media formats are the actual middle-ground production-oriented codecs that support the industry.

MM: There, we're seeing those fairly robust metadata frameworks beginning to grow up. Specifically as they relate to work-in-process, workflow management and so on.

AG: Correct.

MM: At the consumer level, the playout or expression layer. It looks like Flash continues to predominate, in terms of the broad consumer, low-fidelity, AM-radio-quality video.

AG: Yes. That's just due to the simplicity and, at that quality setting - the lightness of it. As you go up in the quality settings, then it becomes a heavier format.

MM: At that playout proxy level, then you're saying that you'll probably also see a similar tier-like effect. Where we have a low-end consumer playout that probably has limited rights management and distribution control mechanisms built into the stream.
AG: Correct.

MM: Can you speak then to the medium and high level? The high level being, probably, a tightly controlled rights-managed stream with high-definition production values. AG: Michael, there's an interesting part about that. I think the high level is yet to-be-determined at that expression level. You've got products out there like Vividas, MoveNetworks, and so on, that provide that high level of quasi-high-entertainment value solutions.

When I'm in the studio and I feel that everything is wrapped around me, great. This is what I've got. But when I'm seeing it at my desktop? We are being told we also could see the same expression on my plasma in my home. However, that is still to-be-determined. It's all over the map.

At this point in time, I'm saying that's all good - but let's keep in mind, you still have to have an open format and an open environment to work with. Having closed codecs that only work with this particular plug-in and this particular solution is probably not the right way to go.

That's why I said, 'To-be-determined.' But that middle ground, which is middle to high, I think is going to fall into ... It's really starting to flow out very well and very quickly to the H264 format.

MM: What are some of the brands, technologies and vendors that lead that particular innovation? AG: Both Microsoft and Adobe, of course ... and in a kluged way ... Microsoft does. They provide it. But which one is better than the other? Probably Adobe, at the moment. But with a very close second calling for Apple and that crew over there.

MM: The tipping point might then relate to the actual distribution point - be it an ITV, Apple, Hulu or some of these other kind of distribution points.

AG: Correct.

Right now, my favorite is Hulu. That's because the content is the forefront. It's not about Hulu. It's about the content. But Hulu is presenting it in such a way that it makes me lean forward instead of lean back.

MM: Hulu being the joint venture of a number of entertainment studios. As I recall, led by NBC and Fox or something like that? 
AG: I think that's correct.

MM: They're putting long-form video content onto Hulu. Of course, because they're doing it themselves, they're able to put into the content appropriate ads and tracking mechanisms to be able to monetize that in terms of a multimedia platform media buy.

AG: That's correct.

What's unknown about Hulu - at least in public - it's actually sitting on the platform's platform.

Which is owned by Comcast. It provides the infrastructure for that. But at the same time, the expression on the front end is Hulu's, and Hulu's alone.

But you touched on a point of really very interesting insight on the monetization component of that delivery, and the actual ability to take that content and wrap dollars around it. Ad revenues. Making sure that that delivery mechanism also comes back to the appropriate strategies to monetize that content.

That strategy really relies on what we talked about earlier in the discussion - about metrics, and the details and the reporting that come out of that player experience and reporting. Right now, they're doing a wonderful job at that. MM: They have a business model and a huge stake in being able to actually validate consumption by very specific consumer cohorts. AG: Correct.

Essentially, they have a wonderful ecosystem to tap into, to drive that downstream.

In theory, when you're talking about reporting in metrics, the holy grail of this is really wrapping the actual metrics inside the content itself. It wouldn't necessarily need to be determined by where its locale is coming from.

By that, I mean that currently the system is set up to centrally place all of the assets to deliver. That delivery mechanism goes through a content-delivery network, and then it's expressed on the player experience, itself.

That player experience is the only quality way to get the appropriate reporting and metrics back to the mother ship - this has to be the place that determines what's happening at the user level. The reporting metrics flow all the way back to the centerpiece.

Again, what I mean by, 'The Holy Grail,' is being able to deliver the metrics no matter where that particular content is flowing through. It would be an evolution in what we're doing with content today than where we are.

What I'm saying is that if you could take the player experience away and then have the content be the essence of the world - then reporting metrics that flow back from that content. Then you'd have the complete essence. Micropublishers would get their piece of the pie just as well as the large broadcast studio or content owner has, today.

Currently, it's a reverse model. If you were able to flip it on its head, then everybody downstream in the ecosystem would get advantages of that.

MM: Right.

In terms of the current state of the art of video metrics, right now whether you post things on YouTube or public things out through Hulu, all $\mathrm{I}$ as the consumer basically knows is that I've got an IP address. Unless there's some opt-in mechanism where I've got now a subscriber profile associated with a session.

I've got the session link. What else do I have in terms of data about the video stream?

AG: We represented the session link. The IP. You get the content format. How long someone was there.

MM: The ISP. In terms of where it came from? AG: ISP. Where it came from, the CDN that's delivering it. The origin it's coming from. That origin could be the origin server that the CDN plugs into. Then back to the user - hopefully understanding when they end their session and when they pick that up, and how much of that was delivered.

MM: So in essence, we really don't know much about the user and how they used the actual content. They log on at this time and they log off at this time. And they spent $x$ amount of time 'in' the session. But not really whether they were engaged or interactive within the stream. AG: Correct.

We're assuming the user is the demographic information that's pulled from that person's desktop, because it could be anyone. It could be someone moving over to my desk or someone moving away. We're making a lot of assumptions, associated with that desktop. MM: That would be the next big breakthrough, to get metrics with respect to the internals of the video stream. 
AG: Correct. No question.

MM: Are there any kinds of early signals among technology innovators in terms of who seems to be making progress in that area? AG: I've heard grumblings of the big boys and some of the other ones. I heard some grumblings over at Sun. I've heard some grumblings over at Microsoft. I'm not really aware of what Adobe's doing and/or the Apple crew.

You would be foolish to assume that Google's not doing something with that, as well. There's no question. That's really where things will be flowing in the next couple of years.

MM: Wouldn't that require that as I publish the content to the Web, that I also publish in the stream the metadata - as it relates to the content subject matter and other sorts of contextual tags, as they might relate to advertising, advertiser-audience acquisition, market segmentation and things like that?

AG: Sure.

Classification and categorization are going to be key in video search engine optimization.

Right now, when a crawler seeks the Web, they're looking at a black blob from the video. If we're able to embed and provide a kernel just like they do in security measures for content ... then your ROI on that particular video stream could run up - if it were processed through an appropriate reader session to then get that additional detail or metadata crawled and found. MM: So right now, video search engine optimization is being done with metatags associated with the blob, as well as textual information of the webpage that contains the blob. Correct?

AG: Correct.

MM: Now we're saying the next frontier of that will entail putting metadata actually into the stream or the video or the proxy, itself.

AG: Without question.

MM: Are there any standards or emerging ideas in terms of how to imprint metadata to a stream?

AG: I'm going to say no. There's a lot of R\&D going on out there in the marketplace. I know that there is a lot of discussion between the SEO world and the video world that's leading $\mathrm{R} \& \mathrm{D}$ to that. But I've not seen a standard out there, to date.

MM: I've heard things from Adobe, with respect to their next Flash server - of their being able to publish XMP metadata to the flash stream.

AG: I'd have to check back with our operations team. I don't know that, to this date. It's been in passing.

MM: It's certainly an opportunity to further lock in the Flash player and create new monetization opportunities for the entire value chain.

AG: Yes. Correct.

MM: In terms of the production of data by which then to do analytics, do you see much innovation from the Akamais or the other CDNs of the world in terms of adding new value to the business ecosystem?

AG: The Akamais, the Level 3s, the High Winds - InterNap. I'm not sure if they're dropping in or out of the CDN business. Around secure streaming and applying mechanisms to help people control their content is really the biggest element that's popping up, recently. It's the most problematic because secure streaming just seems to be a challenge, both from an integration standpoint and a delivery standpoint.

MM: Maybe you can speak to some of the emerging issues and systems around rights management. Just take us through the state of the arts of rights management for video. AG: Well, the state of the DRM. You have Adobe Air, and then all of the Window Media. DRM really falls into those two buckets, right now.

Wrapping and appropriately delivering with some sort of control in this two areas. They're done very differently.

With Windows Media, you can do it from the server environment. But with Flash-based product sets, you actually have to have the player to control that rights management component. It seems to be a stretch.

Now you're controlling the marketplace through a player experience, as compared to having an open 'Let me just capture and preview this content.' Now people are actually having to download that player experience. MM: Looking out now in terms of the next couple or 3 years or so ... What are some of the things that you'd expect to fall into place or emerge as key features of this video ecosystem and/or advertising into it? AG: You look out over the next couple of years, and it's my opinion that the ecosystem 
would be driven down. As we were talking about flipping the ecosystem on its head, and giving the content back to the creator - you're actually going to have technologies out there that help that creator go directly to market. Those technologies are going to be adopted in a far greater fashion.

Twenty per cent of the marketplace can adopt the high technology today. I think as of today, moving toward the 80 per cent rule, that 80 per cent rule which is me - you and anybody else that wants to create quality content. We can go directly to the marketplace, deliver it $24 / 7$, and then have live channels online.

Examples of that - something that just popped up the other day, it's been around for a couple of months. Maybe a year, now. There's a company called Mogulus. Mogulus gives you the ability to have a live webcam or multicamera access ability. A 24/7 channel with the ability to have VOD just running all the time, as you're publishing, yourself.

MM: Would it be fair to say it's kind of the Video Twitter?

AG: It's the Video Twitter - but with much more context behind it. You're getting so much more content, itself. Twitter in-and-out, in-and-out. But this gives you the ability to publish yourself and have your own channel or experience to go direct to market.

I see that that 80 per cent rule and the tools that were this whole broadcast studio will be at your fingertips. That Facebook-like experience and delivery and branding of oneself will be more and more of the here-and-now than it is today.

Over the next couple of years, the different mediums by which we look at things - it's not going to matter. It's just going to be, 'Okay. I'm getting something because I want to get it, and I'm delivering something because I want to deliver it.' It's not going to be about technology.

That whole thing is a term coined as, 'The Media of One.' That will become an experience, finally, in the next 10-15 years. The Media of One is, 'I'm delivering a piece of content. I have appropriate monetization that is associated to the classification or the way in which my affinity group wants to see that. Then it'll be able to be driven downstream.'
MM: That brings me to one last thing I'd like you to address. That is the idea of automated spot insertion into the video stream. As I understand, as a publisher, who you are and what you're consuming, I can then insert appropriate promotional material in the stream, itself. Especially as it relates to longer-form content - such as a half-hour TV show or a 15-minute broadcast.

AG: Without a question.

When we start talking about embedding certain pieces of metadata in the actual content itself, that leads it into the ability to drive that advertising to that specific affinity group. Then when you get to the affinity group, it's just another tweak down the pathway to that individual user.

Without a question, that whole pathway is in front of us. It's going to be driven out because of everybody going completely digital, then the metadata flow from classification to affinity group down to the individual.

MM: That would require the integration and the utilization of three sets of metadata. There's going to be metadata as it relates to what's in the video stream. There's going to be metadata as it relates to the advertising inventory. Specifically, allowing me to sync up the appropriate parts of my ad inventory with appropriate insertion points in the video stream.

The third set of metadata is going to be around the customer and who he or she is, as a demographic profile - target-market participant - consumer/cohort. That sounds like the whole proposition of automated spot-insertion really is a classic DAM/Digital transformation problem to solve, because of the metadata associated with how you triangulate these three sets of metadata to converge at the most propitious and natural, least-intrusive way.

AG: There's no question. As we were discussing at the beginning of our conversation ... I will start from the metadata up. All of these additional technologies and ways in which they intersect will come back to what we've talked about for the last 15 years. The tidal wave of digital content, and how you manage that. You manage that with a DAM centerpiece that then can make those types of things happen.

MM: How close are we to this notion of automated spot insertions, where I'm inserting spots to specific user profiles? 
AG: 36 months.

MM: Do you anticipate the technology of H.264 as the point of entry for that capability? AG: Online. That's correct. And again - to be determined on the crossover codec, or crossover file format. I'm not sure where that crossover is going to be.

MM: So HDTV, provides at least some indication as far as how that would happen. Right?

AG: That's correct.

MM: And the idea that you'd have the ability to broadcast subchannels of appropriate ad spots that could then pierce or puncture into the mainstream or feed of the TV. Or some configuration like that.

AG: Yes. That's correct. I still think it's going to be coming in the notion of a kernel in a piece of content. That then determines, 'I'm going to a set-top box.' But it then determines, 'Oh. This home is owned by Andrew Gregory or it's owned by Michael Moon. There are so many people in there. At this particular point in time, I believe at 10.00 at night, that the man of the house is watching TV or on his computer.'

Determining that that is the appropriate advertising that flows out from there.

MM: I remember having a conversation with a fellow in 1994 in one of these first interactive multimedia conferences in New York City. He'd said that in the late ' 80 s, he'd participated in an interactive TV test trial in Springfield, Massachusetts. In that, they gave some 400 or so households an interactive set-top box, based on a 386 and a Meg of Ram and so on.

Because the interactive content didn't exist, they delivered six or seven different kinds of live feeds. They allowed the consumer to pick from four or eight simultaneous feeds. It was as though the consumer were like the program director, sitting in the truck, calling the show.

They wanted to find out three things. One was, 'Would Grandma want to call her own show?'

'Could we use interactions as they call their own show?' 'Could we use that data to infer a demographic profile and then insert an ad?' Because all the ads broke at the same time. That was the only way they could coordinate it. To insert a demographic, psychographically targeted ad - based on the inferences of the content interaction.

Three, was there any noticeable lift of sales at point-of-sale for the five brands that sponsored this interactive trial?

Their sponsors included a hamburger company, a soda pop company, a snack-food company that you could pick up at a 7-11 or a QuickStop, a car company and an insurance company.

Here's what they found ...

78 or 79 per cent of the consumers did in fact want to call their own show. It skewed younger, but they were surprised by the number of older adults that really wanted to call their own show. In particular, the shows that got the highest level of content interaction entailed those that had live action with multiple points of view.

For example, hockey and basketball had the highest. When you think about it, there's a lot going on in the game. Your point of engagement in one of those types of games can be player-specific. It can be to a particular part of the court or rink, et cetera.

The other thing they discovered when they did the focus groups was that older folks said, 'I learned more about playing tennis by simply putting the large view on Martina Navratilova,' who at that point was the reigning star. 'I studied her.'

There was a close-up of just how she sat on the baseline. They said, 'I learned more about how she works - almost like a tiger or a cat doing a ballet.'

They were really surprised that they could infer the consumer, as a function of interactive content. Specifically, the case that this fellow shared was on MTV. It turns out you could identify - for the most part - a younger cohort, by their consumption of MTV. Furthermore, you could infer the gender, as far as what frames they were looking at.

It turns out that guys are interested in guitar licks and female body parts and more female body parts. Girls, on the other hand, are interested in the backstage ensemble. What's going on on the backstage as far as who's with whom. And fashion. How people look.

As a function of that, they served ads specific to demographic profiles. They found huge lifts in terms of sales, at retail. Fourteen per cent lift in terms of the featured hamburger meal. 
A 23 per cent lift on snack foods and soda pop. A 40 per cent lift in terms of floor traffic into this particular automobile brand. In terms of insurance policies sold at a large department store, known for selling that kind of insurance.

One of the things that their research focus groups had revealed was that when they asked these 400-or-so consumers about the ads, almost without exception, everyone said, 'You know, I didn't really notice the ads all that much. The ones that I did notice were really kind of cool. I really liked them.'

He added as a footnote, the notion of disrupting someone's life and disrupting the narrative of what they were looking at, was not anywhere near as noticeable if you served it to them as it spoke to their needs, criteria and their demographic cohort.

From this, we concluded that automated spot insertions, speaking to very specific consumer cohorts, not only are less intrusive, but they get results at points-of-sale. It works best in particular kinds of venues than others. Theatrical or sports activities.
That basically says to me that for the multi-player/multi-dimensional sports of football, basketball, hockey and so on ... those will probably be the early adopters for this first-to-market automated spot insertion.

One, they have the venue that lends itself most to that kind of spot insertion. And, two, they tend to make a lot of money, anyway. They tend to be early adopters in innovation.

AG: Yes.

I think that the more relevant your advertising is to the affinity group, the more accepting they're going to be to receiving it and/or taking action.

I think that - again - when we start talking about Media of 1, it's going to be definitely tied into the relevance associated to content and advertisers coming together in the appropriate fashion.

MM: That sounds like a great place to conclude this, Andrew. I want to thank you so much. AG: I appreciate the time. Thank you for asking me to do this. 